\title{
The Knowledge of Health Professionals About the Application of Cricoid Pressure in a Low-Income Country: A Single-Center Survey Study
}

This article was published in the following Dove Press journal: International Journal of General Medicine

\section{Metages Hunie $\mathbb{D}^{\prime}$ \\ Tiruwork Desse 2 \\ Diriba Teshome (D) \\ Simegnew Kibret' \\ Moges Gelaw (D) \\ Efrem Fenta (iD)}

'Department of Anesthesia, School of Medicine, College of Health Sciences, Debre Tabor University, Debre Tabor, Ethiopia; ${ }^{2}$ Department of Internal

Medicine, School of Medicine, College of Health Sciences, Debre Tabor University, Debre Tabor, Ethiopia
Correspondence: Metages Hunie Email huniemetages@gmail.com
Background: The application of cricoid pressure requires good knowledge and practice of health professionals who are working in operation theatres to prevent pulmonary aspiration. This study aims to assess the application of cricoid pressure knowledge and practice in health professionals who are working in the operation theatres.

Methods: This survey-based study was conducted in health care professionals who are working in the operation theatre of Debre Tabor Comprehensive Specialized Hospital from November 1 to December 1, 2020. A structured checklist was used to collect data regarding the knowledge and practice of the application of cricoid pressure.

Results: A total of 43 health professionals who are working in the operation theaters were involved in this study with a response rate of $81 \%$. The correct anatomic position of cricoid cartilage was not identified in $67 \%$ of nurses. We found that $78 \%$ of anesthetists did not use the nasogastric tube for decompression, and $83 \%$ of them complain of difficult intubation during the application of cricoid pressure.

Conclusion: Health care professionals who are working in operation theatres had poor knowledge and practice in the application of cricoid pressure.

Keywords: knowledge, practice, health professionals, cricoid pressure

\section{Introduction}

Cricoid pressure is the application of pressure on the cricoid cartilage for patients who undergo surgery under general anesthesia. ${ }^{1-4}$ Applying cricoid pressure is an essential skill of health care professionals who are working in operation theatres, especially anesthetists. ${ }^{5,6}$

The safe practice of cricoid pressure might require good knowledge of its anatomy, technique of application, and complications. ${ }^{7,8}$ The application of cricoid pressure during rapid sequence induction might protect the pulmonary aspiration of gastric contents. ${ }^{9,10}$ The cricoid pressure can result in the rupture of the esophagus when it is applied during vomiting. ${ }^{4,9,11,12}$ An application of cricoid pressure needs an assistant who can locate the cricoid cartilage; apply and release; apply force in the correct direction; apply the correct force, and be able to maintain the force for as long as needed. $5,6,13$

The force applied during cricoid pressure revealed that most assistants used inadequate force, ${ }^{14,15}$ and cricoid pressure may rupture when it is applied during vomiting, ${ }^{16}$ and some assistants may apply too much force that distorts the patient's 
anatomy and might intubation more difficult. ${ }^{17-19}$ An inappropriately applied cricoid pressure warrants evaluation of the cognitive knowledge and application technique of it. ${ }^{6,20-23}$ There were controversies regarding the application of cricoid pressure in preventing pulmonary aspiration. $^{4,24,25}$ The purpose of this study is to assess the application of cricoid pressure knowledge in health professionals who are working in the operation theatres in a low-income country.

\section{Methods}

\section{Study Design, Setting, and Period}

This survey-based study was conducted in Debre Tabor Comprehensive Specialized Hospital which is found in the north-central part of Ethiopia. It is located in the Debub Gondar Zone of the Amhara Region of Ethiopia, about 100 kilometers northeast of Bahir Dar city and 50 kilometers east of Lake Tana, with a latitude and longitude of $11^{\circ} 51^{\prime} \mathrm{N}$ $38^{\circ} 1^{\prime} \mathrm{E}$ and an elevation of 2706 meters ( 8878 feet) above sea level. ${ }^{26}$ The Hospital has 23 anesthetists, 17 physicians (Surgeons, Gynecologists and Orthopedicians), and 13 nurses who are working in four operation theatres. It provides more than 2000 surgical cases annually. The study was conducted from November 1 to December 1, 2020 .

\section{Sampling Technique}

All health care workers who are working in the operation theatres of Debre Tabor Comprehensive Specialized Hospital.

\section{Data Collection Technique}

A structured checklist regarding the knowledge and practice of health care workers who work in the operation theatres of Debre Tabor Comprehensive Specialized Hospital. The checklist for data collection was adopted from different studies. ${ }^{7,27-29}$ The checklist consists of two sections as follows: Section 1: Assessment of knowledge of health care professionals on cricoid pressure application; Some of the questions were: where did you learn to apply cricoid pressure, where does cricoid cartilage lie, and use of cricoid pressure, etc. Section 2: Assessment of the practice of cricoid pressure in anesthetists; Some of the questions were: do you routinely mask ventilate during rapid sequence induction, do you decompress the stomach by nasogastric tube before rapid sequence induction, do you remove the nasogastric tube before rapid sequence induction, have you witnessed regurgitation during application of cricoid pressure, and have you experienced difficulty to intubate during application of cricoid pressure. After taking oral and written informed consent, study participants were asked to fill up the English version checklist about their routine practice and knowledge regarding cricoid pressure application.

\section{Data Analysis}

Data were checked manually for completeness, coded and entered into SPSS version 23 computer program for analysis. Descriptive statistics were employed to summarize the results by frequencies and percentages.

\section{Data Quality Control}

The investigators cross-checked for the completeness, and consistency of the data before data analysis.

\section{Results}

\section{Knowledge of Cricoid Pressure Application}

A total of 43 out of 53 health professionals who are working in the operation theater (18 anesthetists, 13 physicians, and 12 nurses) were involved in the study, which yielded a response rate of $81 \%$. The correct anatomic position of cricoid cartilage was identified by $94 \%$, $100 \%$, and $33 \%$ of anesthetists, physicians, and nurses, respectively. Sixty-seven percent of nurses replied cricoid pressure is applied to prevent pulmonary aspiration during induction of anesthesia (Table 1).

\section{The Practice of Cricoid Pressure Application}

The majority (83\%) of anesthetists complain of difficulty to intubate during the application of cricoid pressure and $72 \%$, of the respondents, have witnessed regurgitation during application of cricoid pressure (Table 2).

\section{Discussion}

Even though the efficacy of cricoid pressure in preventing pulmonary aspiration had controversial results, ${ }^{2,25}$ it is better to at least try to prevent aspiration with cricoid pressure in a low-income country to prevent serious postoperative sequelae and it may be of huge importance for a low-income setting where intensive care beds are very scarce. 
Table I Assessment of Knowledge of Health Care Professionals on Cricoid Pressure Application at Debre Tabor Comprehensive Specialized Hospital, $2020(n=43)$

\begin{tabular}{|c|c|c|c|c|c|c|c|}
\hline \multicolumn{2}{|l|}{ Knowledge on Cricoid Pressure } & \multicolumn{2}{|c|}{ Anesthetists } & \multicolumn{2}{|l|}{ Physician } & \multicolumn{2}{|l|}{ Nurse } \\
\hline & & \multirow{2}{*}{$\begin{array}{l}\text { Number } \\
10\end{array}$} & \multirow{2}{*}{$\begin{array}{l}\% \\
56\end{array}$} & \multirow{2}{*}{$\frac{\text { Number }}{13}$} & \multirow{2}{*}{$\frac{\%}{100}$} & \multirow{2}{*}{$\begin{array}{l}\text { Number } \\
9\end{array}$} & \multirow{2}{*}{$\begin{array}{l}\% \\
75\end{array}$} \\
\hline $\begin{array}{l}\text { Where did you learn to apply cricoid } \\
\text { pressure? }\end{array}$ & $\begin{array}{l}\text { Shown on a patient during clinical } \\
\text { practice or student attachment }\end{array}$ & & & & & & \\
\hline & By reading only & 0 & 0 & 0 & 0 & 2 & 17 \\
\hline & By practicing on a model or manikin & 8 & 44 & 0 & 0 & I & \\
\hline & I have never been taught about it & 0 & 0 & 0 & 0 & 0 & 8 \\
\hline \multirow[t]{4}{*}{ Where does cricoid cartilage lie } & In front of the thyroid cartilage & 1 & 6 & 0 & 0 & 1 & 9 \\
\hline & Behind the thyroid cartilage & 0 & 0 & 0 & 0 & 4 & 33 \\
\hline & Below the thyroid cartilage & 17 & 94 & 13 & 100 & 4 & 33 \\
\hline & Behind the esophagus & 0 & 0 & 0 & 0 & 3 & 25 \\
\hline \multirow[t]{4}{*}{ Use of cricoid pressure } & $\begin{array}{l}\text { Prevent aspiration of stomach contents } \\
\text { during induction of anesthesia }\end{array}$ & 18 & 100 & 13 & 100 & 8 & 67 \\
\hline & $\begin{array}{l}\text { Prevent patient breathing during } \\
\text { anesthesia }\end{array}$ & 0 & 0 & 0 & 0 & 4 & 33 \\
\hline & $\begin{array}{l}\text { Prevent patient vomiting during } \\
\text { anesthesia }\end{array}$ & 0 & 0 & 0 & 0 & 0 & 0 \\
\hline & $\begin{array}{l}\text { Prevent gastric gas insufflation during bag } \\
\text { mask ventilation }\end{array}$ & 0 & 0 & 0 & 0 & 0 & 0 \\
\hline \multirow[t]{5}{*}{ cricoid pressure in awake patient } & $10 \mathrm{~N}$ & 10 & 56 & 0 & 0 & I & 8.5 \\
\hline & $20 \mathrm{~N}$ & 6 & 33 & 0 & 0 & I & 8.5 \\
\hline & $30 \mathrm{~N}$ & 2 & 11 & 0 & 0 & 0 & 0 \\
\hline & $50 \mathrm{~N}$ & 0 & 0 & 0 & 0 & 0 & 0 \\
\hline & Do not know & 0 & 0 & 13 & 100 & 10 & 83 \\
\hline \multirow[t]{5}{*}{ cricoid pressure in anesthetized } & $10 \mathrm{~N}$ & 2 & 11 & 0 & 0 & 0 & 0 \\
\hline & $20 N$ & 0 & 0 & 0 & 0 & 0 & 0 \\
\hline & $30 \mathrm{~N}$ & 10 & 56 & 0 & 0 & 2 & 17 \\
\hline & $50 \mathrm{~N}$ & 6 & 33 & 0 & 0 & 0 & 0 \\
\hline & Do not know & 0 & 0 & 0 & 0 & 10 & 83 \\
\hline \multirow[t]{4}{*}{$\begin{array}{l}\text { Correct measure if a patient vomit during } \\
\text { cricoid pressure Application }\end{array}$} & $\begin{array}{l}\text { Maintain the same force and suction the } \\
\text { patient's pharynx }\end{array}$ & 2 & 11 & 8 & 62 & 3 & 25 \\
\hline & $\begin{array}{l}\text { Increase the force and suction the } \\
\text { patient's pharynx }\end{array}$ & 2 & II & 3 & 23 & 3 & 25 \\
\hline & $\begin{array}{l}\text { Decrease the force and suction the } \\
\text { pharynx }\end{array}$ & 2 & 11 & 0 & 0 & 5 & 42 \\
\hline & $\begin{array}{l}\text { Release the force and suction the } \\
\text { patient's pharynx }\end{array}$ & 12 & 67 & 2 & 15 & I & 8 \\
\hline
\end{tabular}


Table I (Continued).

\begin{tabular}{|l|l|l|l|l|l|l|l|}
\hline Knowledge on Cricoid Pressure & \multicolumn{2}{l|}{ Anesthetists } & \multicolumn{2}{l|}{ Physician } \\
\cline { 3 - 7 } & & Number & $\%$ & Number & $\%$ & Number & $\%$ \\
\hline \multirow{5}{*}{ When to release cricoid pressure } & After intubation & 0 & 0 & 5 & 38.5 & 5 \\
\cline { 2 - 7 } & After inflation of the cuff & 2 & 11 & 3 & 23 & 2 \\
\cline { 2 - 7 } & $\begin{array}{l}\text { After confirmation the position of } \\
\text { endotracheal tube }\end{array}$ & 16 & 89 & 5 & 38.5 & 4 \\
\cline { 2 - 7 } & I do not know & 0 & 0 & 0 & 0 & 1 \\
\hline
\end{tabular}

Note: N, Newton.

Table 2 Assessment of the Practice of Cricoid Pressure in Anesthetists Who are Working at Debre Tabor Comprehensive Specialized Hospital, $2020(n=18)$

\begin{tabular}{|l|l|l|l|}
\hline \multicolumn{2}{|l|}{ Practice of Cricoid Pressure } & Number of Anesthetists & $\%$ \\
\hline Do you routinely mask ventilate during rapid sequence induction & $\begin{array}{l}\text { Yes } \\
\text { No }\end{array}$ & $\begin{array}{l}5 \\
13\end{array}$ & $\begin{array}{l}28 \\
72\end{array}$ \\
\hline Do you decompress the stomach by nasogastric tube before rapid sequence induction & $\begin{array}{l}\text { yes } \\
\text { no }\end{array}$ & $\begin{array}{l}4 \\
14\end{array}$ & $\begin{array}{l}22 \\
78\end{array}$ \\
\hline Do you remove nasogastric tube before rapid sequence induction? & Yes & 3 & 17 \\
\hline Have you witnessed regurgitation during application of cricoid pressure? & No & 15 & 83 \\
\hline Have you experienced difficulty to intubate during application of cricoid pressure? & Yes & 5 & $\begin{array}{l}\text { Yes } \\
\text { No }\end{array}$ \\
\hline
\end{tabular}

The lack of knowledge regarding the application of cricoid pressure in health care professionals who are working in operation theatres may increase the risk of aspiration of gastric contents, rupture of the esophagus, aggravation of cervical spine injury, makes difficult tracheal intubation, and complete airway obstruction., ${ }^{3,30-33}$

This study revealed that the knowledge on the anatomical structure of cricoid cartilage was insufficient in nurses (33\%), whereas anesthetists (94\%) and physicians $(100 \%)$ had good knowledge in identifying it. Our study showed that there was a significant knowledge gap in the identification of the cricoid cartilage. In line with our finding some studies reported that health care professionals had poor knowledge in identifying the cricoid cartilage, the amount of cricoid pressure force required, and the correct application of cricoid pressure. ${ }^{2,34,35}$ Most of our study participants had poor knowledge and skill regarding when cricoid pressure is released. Similarly, research conducted by Krishnan et al health professionals had inadequate knowledge when cricoid pressure is released. ${ }^{28}$

We found that $72 \%$ of anesthetists did not mask ventilate during rapid sequence induction and $78 \%$ of them did not use the nasogastric tube for decompression, $28 \%$ of the anesthetists witnessed regurgitation during application of cricoid pressure, and $83 \%$ of anesthetists complain of difficult intubation during application of cricoid pressure. Similarly to our finding, a study done by Etanaa et al reported that $90 \%$ of the respondents do not mask ventilate during rapid sequence induction. Ninety-three percent of anesthetists did not remove the nasogastric tube before rapid sequence induction, and $70 \%$ complain of difficult intubation during the application of cricoid pressure. $^{7}$ 


\section{Conclusion}

All health care professionals who are working in operation theatres had deficient knowledge in the application of cricoid pressure. Educational interventions are needed to improve knowledge and hence the practice of cricoid pressure application.

\section{Ethical Consideration}

Ethical clearance was obtained from Debre Tabor University Ethical Review Committee. Written informed consent was secured from each study participant after the aim of the study is disclosed.

This study was conducted in accordance with the Declaration of Helsinki.

\section{Acknowledgments}

Debre Tabor University.

\section{Author Contributions}

All authors made a significant contribution to the work reported, whether that is in the conception, study design, execution, acquisition of data, analysis and interpretation, or in all these areas; took part in drafting, revising or critically reviewing the article; gave final approval of the version to be published; have agreed on the journal to which the article has been submitted; and agree to be accountable for all aspects of the work.

\section{Funding}

There is no funding to report.

\section{Disclosure}

The authors report no conflicts of interest for this work.

\section{References}

1. Sellick B. Cricoid pressure to control regurgitation of stomach contents during induction of anaesthesia. lancet. 1961;278 (7199):404-406. doi:10.1016/S0140-6736(61)92485-0

2. Yahaya NH, Teo R, Izaham A, Tang S, Yusof AM, Manap NA. [Analysis of cricoid pressure application: anaesthetic trainee doctors vs. nursing anaesthetic assistants].. Rev Bras Anestesiol. 2016;66 (3):283-288. doi:10.1016/j.bjan.2016.02.013

3. Landsman I. Cricoid pressure: indications and complications. Pediatric Anesthesia. 2004;14(1):43-47. doi:10.1046/j.14609592.2003.01202.x

4. Zdravkovic M, Rice MJ, Brull SJ. The clinical use of cricoid pressure: first, do no harm. Anesth Analg. 2021;132(1):261-267. doi:10.1213/ ANE. 0000000000004360

5. Owen H, Follows V, Reynolds K, Burgess G, Plummer J. Learning to apply effective cricoid pressure using a part task trainer. Anaesthesia. 2002;57(11):1098-1101. doi:10.1046/j.1365-2044.2002.02836.x
6. Salem MR, Khorasani A, Zeidan A, Crystal GJ. Cricoid Pressure ControversiesNarrative Review. Anesthesiology. 2017;126 (4):738-752. doi:10.1097/ALN.000000000001489

7. Etanaa NB, Benwu KM. A survey of cricoid pressure application in a single institution in Ethiopia. BMC Res Notes. 2019;12(1):546. doi:10.1186/s13104-019-4586-4

8. Holmes N, Martin D, Begley AM. Cricoid pressure: a review of the literature. J Perioper Pract. 2011;21(7):234-238. doi:10.1177/ 175045891102100702

9. Ramaiah R, Stewart J, Bhananker S. Rapid-sequence intubation and cricoid pressure. Int J Crit Illn Inj Sci. 2014;4(1):42. doi:10.4103/ 2229-5151.128012

10. Fenton P, Reynolds F. Life-saving or ineffective? An observational study of the use of cricoid pressure and maternal outcome in an African setting. Int $J$ Obstet Anesth. 2009;18(2):106-110. doi:10.1016/j.ijoa.2008.07.006

11. Vanner R, Asai T. Safe Use of Cricoid Pressure. Wiley Online Library; 1999.

12. Melia D. Cricoid pressure during rapid sequence induction: using the force or not. $\mathrm{Br} J$ Hosp Med. 2015;76(12):730. doi:10.12968/ hmed.2015.76.12.730

13. Birenbaum A, Hajage D, Roche S, et al. Effect of cricoid pressure compared with a sham procedure in the rapid sequence induction of anesthesia: the IRIS randomized clinical trial. JAMA Surg. 2019;154 (1):9-17. doi:10.1001/jamasurg.2018.3577

14. Navsa N, Tossel G, Boon J. Dimensions of the neonatal cricothyroid membrane - how feasible is a surgical cricothyroidotomy? Pediatric Anesthesia. 2005;15(5):402-406. doi:10.1111/j.1460-9592. 2005.01470.x

15. Ogura JH, Biller HF. Reconstruction of the larynx following blunt trauma. Ann Otology Rhinol Laryngol. 1971;80(4):492-506. doi:10.1177/000348947108000411

16. Heath K, Palmer M, Fletcher S. Fracture of the cricoid cartilage after Sellick's manoeuvre. $\mathrm{Br} \quad J$ Anaesth. 1996;76(6):877-878. doi:10.1093/bja/76.6.877

17. Bowyer L. The Confidential Enquiry into Maternal and Child Health (CEMACH). Saving Mothers' Lives: Reviewing Maternal Deaths to Make Motherhood Safer 2003-2005. The Seventh Report of the Confidential Enquiries into Maternal Deaths in the UK. London, England: SAGE Publications Sage UK; 2008.

18. Weindling A. The confidential enquiry into maternal and child health (CEMACH). Arch Dis Child. 2003;88(12):1034-1037. doi:10.1136/ adc.88.12.1034

19. Trethewy CE, Burrows JM, Clausen D, Doherty SR. Effectiveness of cricoid pressure in preventing gastric aspiration during rapid sequence intubation in the emergency department: study protocol for a randomised controlled trial. Trials. 2012;13(1):1-6. doi:10.1186/1745-6215-13-17

20. Beavers RA. Analysis of Application of Cricoid Cartilage Pressure. University of Kansas; 2008

21. Ho AM-H, Wong W, Ling E, Chung DC, Tay BA. Airway difficulties caused by improperly applied cricoid pressure. J Emerg Med. 2001;20(1):29-31. doi:10.1016/S0736-4679(00)00285-7

22. Chaney B, Brady MF. Sellick Maneuver (Cricoid Pressure). StatPearls [Internet]; 2020.

23. Xue N, Liu C, Sun J, et al. Miniature force sensing system for monitoring of optimal cricoid pressure for airway protection. IEEE Sens J. 2018;18(10):4303-4310. doi:10.1109/ JSEN.2018.2821697

24. Zdravkovic M, Berger-Estilita J, Sorbello M, Hagberg C. An international survey about rapid sequence intubation of 10,003 anaesthetists and 16 airway experts. Anaesthesia. 2020;75(3):313-322. doi:10.1111/anae.14867

25. Loganathan N, Liu E. Cricoid pressure: ritual or effective measure? Singapore Med J. 2012;53(9):620-622. 
26. Autor C. Assessment of Productive and Reproductive Performances of Cross Breed Dairy cows in Debre tabor town. Assessment. 2014;4:23

27. Howells T, Chamney AR, Wraight W, Simons R. The application of cricoid pressure. An assessment and a survey of its practice.. Anaesthesia. 1983;38(5):457-460. doi:10.1111/j.1365-2044.1983. tb14030.x

28. Krishnan B, Sanjib D, Harikrishna D, Rajlakshmi B, Korula G. Cricoid pressure: a survey of its practice in India. Indian J Anaesth. 2007;51(6):505.

29. Vanner R. Tolerance of cricoid pressure by conscious volunteers. Int J Obstet Anesth. 1992;1(4):195-198. doi:10.1016/0959-289X (92)80005-D

30. Georgescu A, Miller JN, Lecklitner ML. The Sellick maneuver causing complete airway obstruction. Anesth Analg. 1992;74(3):457-459. doi:10.1213/00000539-199203000-00022

31. Brimacombe JR, Berry AM. Cricoid pressure. Canadian J Anaesthesia. 1997;44(4):414-425. doi:10.1007/BF03014464
32. Escott M, Owen H, Strahan A, Plummer J. Cricoid pressure training: how useful are descriptions of force? Anaesth Intensive Care. 2003;31(4):388-391. doi:10.1177/0310057X0303100406

33. Boet S, Duttchen K, Chan J, et al. Cricoid pressure provides incomplete esophageal occlusion associated with lateral deviation: a magnetic resonance imaging study. $J$ Emerg Med. 2012;42 (5):606-611. doi:10.1016/j.jemermed.2011.05.014

34. Koziol CA, Cuddeford JD, Moos DD. Assessing the force generated with application of cricoid pressure. AORN J. 2000;72(6):1018-1030. doi:10.1016/S0001-2092(06)61907-8

35. Nafiu OO, Bradin S, Tremper KK. Knowledge, Attitude, and Practice Regarding Cricoid Pressure of ED Personnel at a Large U.S. Teaching Hospital. J Em Nursing. 2009;35(1):11-15. doi:10.1016/j. jen.2008.01.009

\section{Publish your work in this journal}

The International Journal of General Medicine is an international, peer-reviewed open-access journal that focuses on general and internal medicine, pathogenesis, epidemiology, diagnosis, monitoring and treatment protocols. The journal is characterized by the rapid reporting of reviews, original research and clinical studies across all disease areas. The manuscript management system is completely online and includes a very quick and fair peer-review system, which is all easy to use. Visit http://www.dovepress.com testimonials.php to read real quotes from published authors. 